\title{
Deinstitutionalization and The Homeless Mentally III
}

\author{
Sarada Menon ${ }^{1}$, Jayakumar Menon ${ }^{2}$, P. Poornachandrika ${ }^{3}$
}

A ccording to the Oxford dictionary "Institution" is an important public body, a home providing care for people with special needs and 'institutionalise' is placing such persons in a residential institution. In the context of the topic being discussed, institution is a home for persons with special needs and similarly institutionalisation is placing the persons with serious mental illness, whether acute, subacute or chronic. Deinstitutionalisation is increasingly being projected as the most needed reform in the mental health care by many experts in our country, but the implications of this merit's critical evaluation.

Institutions for the mentally ill have many rules, regulations and restrictions which are necessary for the patients' own safety, and wellness. As the patient improves, the extent and quality of the restrictions can be gradually reduced and finally withdrawn completely. This is associated with discharge and placement of the person in an appropriate residential facility. It is extremely important that the timing of these relaxations is determined only by a competent medical professional, the psychiatrist. Hence it also becomes mandatory that periodic detailed reviews are done to justify the level of freedom and restrictions. Most of the modern societies ensure appropriate checks and balances are in place so that individual rights are not trampled. The mental health act in most developed nations and now in India underscore this principle and is carefully drafted to reflect on these guiding principles of medical ethics.

When symptom free and manageable, the patient has to be discharged home and the treatment continued in outpatient basis, along with reviews, rehabilitation interventions, eg: recreation, occupational therapy, family education, supported employment, place and train approaches to achieve financial, social, emotional and personal independence. If followed carefully, the result can be expected to be successful.

If the family cannot or will not take the person home as advised, the multi-disciplinary team needs to find out the barriers to returning home and the reasons for the family's reluctance. If the patient does not go home then a transfer to an after-care home is the next option. In the after-care home, the type of care will differ. Selfdiscipline, personal care, communication opportunities, introduction to work and relaxation exercises (outdoor and indoor games, reading, music etc.,) forms the focus of attention. Work as a form of therapy in the beginning and later for a livelihood finds a place now. The residents are to be divided among the staff and each staff should have a fixed number of patients under him or her. This is akin to case management, the staff member must become a friend and mentor to the patient and learn all about the patient - life story, work ability, interests, and plan for training in the job he or she is capable of taking up. If there are not enough staff for this, volunteers like family members or from schools of social work and NGOs need to be actively involved in taking it up.

Clients in a home with large number of inmatestend generally,to find it difficult to get proper personal attention and fall into a mechanical routine, a habit which is difficult for them to give up. They gradually lose interest in everything, and become content and reluctant to move. The caregiver also loses interest and the client continues to "just exist", not living and resistant to change. Indifference on both sides results in the client becoming institutionalised.

${ }^{1}$ Retd.Professor of Psychiatry, Madras Medical Collegeand Former Superintendent, Institute of Mental Health, Kilpauk, Chennai, Tamilnadu; ${ }^{2}$ Clinical Lead, Anbagam-TERDOD and Adjunct Faculty, Department of Psychiatry, Sri Ramachandra Institute of Higher Education, Porur, Chennai; ${ }^{3}$ Professor of Psychiatry, Madras Medical College and Director (FAC), Institute of Mental Health, Kilpauk, Chennai, Tamilnadu. 
Deinstitutionalisation is essential to prevent such a situation. It arises from inadequate attempts to discharge the patients as soon as he or she is manageable, may be due to ignorance of consequences. No client in a vocational training center is to be kept for more than 6 months. No client in an aftercare home should be allowed to stay for more than 1 year. Where can we send them?

Discharges to other places than "homes" like,

1 Smaller residential units with 5-20 people in each in the community, from where they can go out and get meaningful employment in the society

2 To other institutions dealing with a different set of population - like old age homes, intellectually disabled homes, hospital premises, temple authorities etc., in small numbers, where they have a better chance of further recovery, with change in the environment, resulting in better socialising and chance of working towards their own future.

The discharges should be gradual, in small numbers to understanding, cooperative organisations who work with this spirit of individual freedom and inclusiveness in the community. No patient should be a permanent responsibility of a tertiary teaching institution or an acute treatment center. Every staff member should know this fundamental goal of treatment, and work towards finding a home and dignified existence for the individual with serious mental illness in the community.

The guiding principle of care for those with serious mental illness has to be based on their response to the treatment initially and the course of the illness. Those who have responded well to medication and are asymptomatic, will need to get back to the mainstream as soon as possible. A detailed occupational therapy assessment, neuropsychological assessment (need based) and functional assessment help in determining the future course of supports and care required. The more severely and persistently symptomatic individuals will need inpatient rehabilitation, half way homes and then step down to the community based residential services.

\section{The homeless mentally ill conundrum:}

One of the least researched seriously mentally ill (SMI) patient group in India is the homeless men-tally ill ${ }^{1,2}$. As per the scarce literature evidence from this part of the country, homeless and wandering mentally ill are, as a group, much more severely ill, more disabled and have a more severe course of the illness ${ }^{3,4,5}$. Homelessness as such has not been researched much and nor has it been properly defined by mental health services in our context. While there has been a general trend to highlight that care for the serious mentally ill is being provided by families in low- and middle-income countries that lack community based mental health services, recent years have shown a rapid change in these perceptions. Much more SMI individuals are finding themselves without family support, and left to the care of the overcrowded and underfunded government institutions and NGOs for long term stay.

The wandering mentally ill individuals form a sizeable cluster of SMI in any major metropolitan city in India. These individuals are often from other states or from far corners of the country, most often with poor nutrition, no treatment and with no resting places. While concerted government programs that specifically cater to this population are in their nascency, psychiatric tertiary care centres, even with insufficient resources, have always been open to admit, treat and rehabilitate these patients. Many NGOs have also been involved in providing rescue, treatment, rehabilitation and reintegration ${ }^{6}$. The response to treatment and recovery of these individuals is variable, and an individualised planning is often needed taking into consideration the strengths, weaknesses, goals and aspirations, with sufficient care given to ensure dignity and support in their life journey.

The bottleneck in most of the tertiary care institutions, some of them older asylums, is that most of these severely ill homeless SMI individuals who end up there have neither family support nor any community residential facilities that can cater to their increased level of care. One of the problems with activism towards deinstitutionalisation is that they are blind to the clinical reality of illness severity and try to club all patients in one single lot creating a simplified and idealistic 'rescue to recovery' narrative. Some of the non-governmental organisations are very selective in providing communitybased work, choosing to work with the most capable and functionally recovered patients and claim success in their endeavour. The more severely ill and disabled are conveniently transferred to the very same institutions that they sometimes disparage! 
The need of the hour is a much more pragmatic and empathetic response to care ${ }^{7,8,9,10}$, suitable to the country's needs and the prevailing social situation. There is an urgent need for government to step in and develop community-based rehabilitation and recovery models that are realistic, sustainable and replicable. Focusing on deinstitutionalisation as a goal by itself can be counterproductive as is evident from examples across the world. In the United Kingdom and in Australia, where asylums were pulled down and acute care beds were reduced to cut costs in the 1990s, there were many in-stances of chronically ill patients receiving no sustained care or having access to safe accommodation options in the community. ${ }^{11}$ There was an unprecedented increase in emergency mental health visits and adverse outcomes. This led to revision of policies to incorporate affordable housing as an essential component of ongoing care. One must understand that this was in spite of a well-established community care service in those countries. ${ }^{4}$
India with its burgeoning population of 1.4 billion people is moving towards a more modern society with fewer traditional family systems in place. One can already see a dramatic increase in demands for long term care for the SMI by institutions (whether State run or Private or NGOs) owing to this. Deinstitutionalisation targeting the larger tertiary care institutions while neglecting the mushrooming of long stay institutions in private and NGO sector is evidently a poor plan. Executing this hastily without a comprehensive back up plan by the government to provide affordable, safe and supervised long term residential facilities for this most seriously ill patient group will be the harbinger of chaos in mental health care. It will be worth considering incorporating various religious, spiritual and social welfare organisations to establish community housing services for the mentally ill as part of their welfare schemes. A coordinated and mutually respectful effort is needed between the government, traditional long stay care centres, NGOs and the community to bring a positive change to the current scenario.

\section{REFERENCES}

1. Tripathi A, Nischal A, Dalal PK, et al. Sociodemographic andclinical profile of homeless mental-ly ill inpatients in a north Indian medical university. Asian Journal of Psychiatry. 2013;6(5):404-409

2. Gowda GS, Telang A, Sharath CR, et al. Use of newer technologies with existing service for family reintegration of unknown psychiatric patients: A case series. Asian Journal of Psychiatry. 2017;43:205-207

3. Gowda GS, Gopika G, Kumar CN, et al. Clinical outcome and rehabilitation of homeless mental-ly ill patients admitted in mental health institute of South India: 'Know the Unknown' project. Asian Journal of Psychiatry. 2017;30:49-53

4. Rosenheck R. Cost-effectiveness of services for mentally ill homeless people: the application of research to policy and practice. American Journal ofPsychiatry. 2000;157(10):1563-1570

5. Singh G, Shah N, Mehta R. The Clinical Presentation and Outcome of the Institutionalized Wan-dering Mentally Ill in India. Journalof Clinical and Diagnostic Research. 2016;10(10):VC13-VC16

6. Rao PN. Rehabilitation of the wandering seriously mentally ill (WSMI) women-The Banyan ex-perience. Social Work inHealth Care. 2004;39(1-2):49-65

7. Montgomery AE, Metraux S, Culhane D. Rethinking Homelessness Prevention among Persons with Serious Mental Illness. Social Issues and Policy Review. 2013;7(1):58-82

8. Kerman N, Sylvestre J, Aubry T, et al. Predictors of Mental Health Recovery in Homeless Adults with Mental Illness. Community Mental Health Journal. 2019;55(4):631-640

9. Folsom DP, Hawthorne W, Lindamer L, et al. Prevalence and Risk Factors for Homelessness and Utilization of Mental Health ServicesAmong 10,340 Patients With Serious Mental Illness in a Large Public Mental Health System. American Journal of Psychiatry. 2005;162(2):370-376

10. Gabrielian S, Young AS, Greenberg JM,et al. Social support and housing transitions among homeless adults with serious mental illness and substance use disorders. Psychiatric Rehabilita-tion Journal. 2018;41(3):208-215

11. Lamb HR. Deinstitutionalization at the beginning of the new millennium. Harvard Review Psychiatry.1998;6(1):1-10 